\title{
Fetal blood flow measured using phase contrast MRI-comparison of image quality and flow volume at $1.5 \mathrm{~T}$ with $3.0 \mathrm{~T}$
}

\author{
Beverly Tsai-Goodman ${ }^{3 *}$, Mike Seed ${ }^{2}$, Christopher Macgowan ${ }^{1}$ \\ From 18th Annual SCMR Scientific Sessions \\ Nice, France. 4-7 February 2015
}

\section{Background}

Ultrasound is commonly used for the antenatal assessment of a fetus and it can provide functional and haemodynamic data in addition to anatomical details. The accuracy of the former is dependant on angle of insonation, maternal habitus and fetal position. Phase contrast cardiovascular magnetic resonance (PC CMR) has emerged as a clinical tool for blood flow quantification but its use in the foetus has been hampered by the need for gating with the fetal heart beat. Previously described metric optimized gating (MOG) technique has been successfully used to measure fetal blood flow in late gestation foetuses on a 1.5T MRI magnet. However, there is increasing interest in performing foetal cardiac imaging using 3.0T MRI. We describe our pilot data of fetal blood flow measured in 3.0T MRI using MOG technique.

\section{Methods}

Fetal blood flows were quantified in 5 subjects at late gestational age (35-38 weeks) of which were two normal and three pregnancies with ventricular size discrepancy. The data were obtained on $1.5 \mathrm{~T}$ and 3.0T (Siemens Avanto and TRIO, respectively) within the same day using a previously described protocol. After MOG reconstruction of PC MR data, blood flow was quantified by using $\mathrm{Q}$ flow (Medis, NL) and adjusted for fetal mass. Reproducibility of flow measurements at the two field strengths was assessed by Pearson correlation coefficient $\left(R^{2}\right)$, linear regression and Bland Altman analysis.

\section{Results}

PC CMR flow measurements were obtained in 31 of 35 target vessels. A correlation plot showed strong agreement

${ }^{3}$ Royal Hospital for Sick Children, Bristol, UK

Full list of author information is available at the end of the article between corresponding measurements at each field strength $\left(R^{2}=0.78\right.$, slope $\left.=0.83 \pm 0.11\right)$ with a mean and $95 \%$ confidence interval (C.I.) of $-1 \mathrm{ml} / \mathrm{min} / \mathrm{kg}$ and $71 \mathrm{ml} / \mathrm{min} / \mathrm{kg}$, respectively (Fig. 1). Across all

(a)

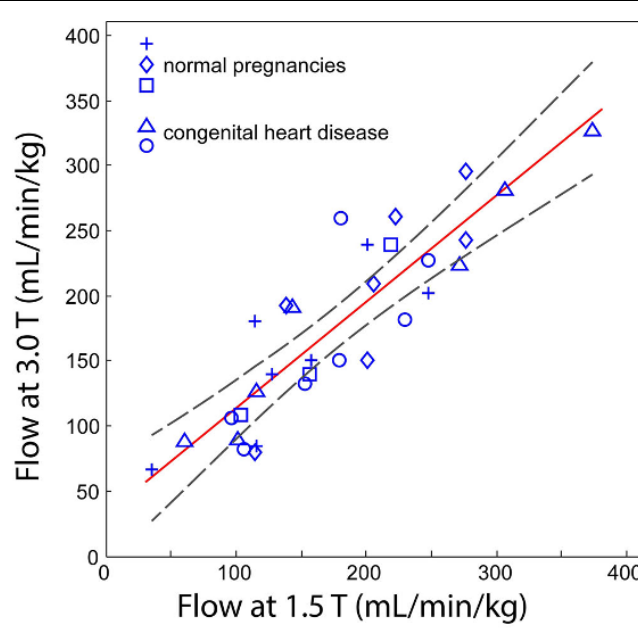

(b)

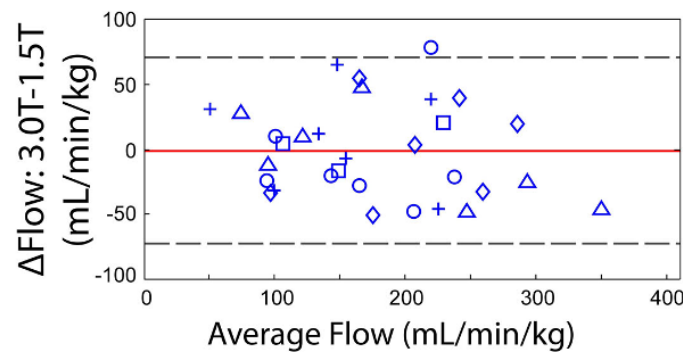

Figure 1 (a) Comparison of fetal flows (5 subjects) measured at 3.0T versus $1.5 \mathrm{~T}$ using PC CMR with MOG. Solid red line = linear regression; Dashed lines $=95 \%$ confidence interval $(\mathrm{Cl})$ (b) BlandAltman analysis of data from (a). Solid red line $=$ mean; Dashed $=$ $95 \% \mathrm{Cl}$ 
(a)

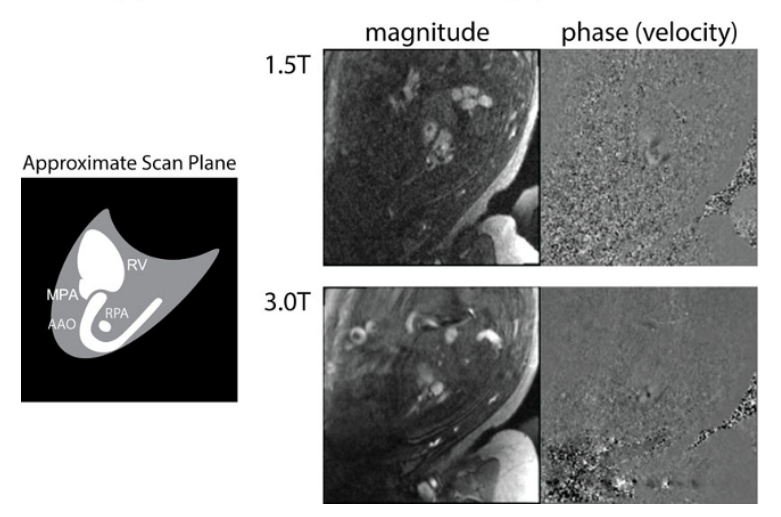

(b)

(c)

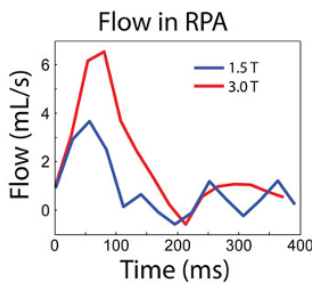

peak SNR

$1.5 \mathrm{~T}=6.5$

$3.0 \mathrm{~T}=11.0$

Figure 2 Comparison of PC CMR of the RPA at 1.5 T and 3.0 T. (a) Diagram of slice orientation through the fetal anatomy showing major vascular landmarks. (b) Magnitude and phase (velocity) data at 1.5 and $3.0 \mathrm{~T}$, demonstrating superior SNR and anatomical visualization at $3.0 \mathrm{~T}$.

(c) Corresponding flow waveforms obtained from the RPA at $1.5 \mathrm{~T}$ (blue) and 3.0 T (red), and peak SNR (per pixel) for the RPA. RV = Right ventricle.

measurements, SNR at $3.0 \mathrm{~T}$ was increased by $165 \pm 16 \%$ relative to $1.5 \mathrm{~T}$ and this was more noticeable the smaller the vessel (Fig. 2).

\section{Conclusions}

This is the first pilot study to measure fetal blood flow using MOG in 3.0T field strength. The flow data obtained were in good correlation with those measured at 1.5T. Due to increase SNR and therefore better visualization of the smaller vessels, the MOG algorithm and the final flow measurements were much improved.

\section{Funding}

None.

\section{Authors' details}

${ }^{1}$ University of Toronto, Toronto, ON, Canada. ${ }^{2}$ The Hospital for Sick Children, Toronto, ON, Canada. ${ }^{3}$ Royal Hospital for Sick Children, Bristol, UK.

Published: 3 February 2015

doi:10.1186/1532-429X-17-S1-060

Cite this article as: Tsai-Goodman et al:: Fetal blood flow measured using phase contrast MRI-comparison of image quality and flow volume at 1.5T with 3.0T. Journal of Cardiovascular Magnetic Resonance 2015 17(Suppl 1):060.

\section{Submit your next manuscript to BioMed Central} and take full advantage of:

- Convenient online submission

- Thorough peer review

- No space constraints or color figure charges

- Immediate publication on acceptance

- Inclusion in PubMed, CAS, Scopus and Google Scholar

- Research which is freely available for redistribution

Submit your manuscript at www.biomedcentral.com/submit
Biomed Central 